\title{
PERSONALIZED CHARACTERISTICS OF MORPHOMETRIC AND FUNCTIONAL PARAMETERS OF RETINA IN ARTERIAL HYPERTENTION ACCORDING TO OPTICAL COHERENCE TOMOGRAPHY-ANGIOGRAPHY DATA
}

\author{
Olesia Moroz \\ Senior Lecturer, Ivano-Frankivsk National Medical University, Ukraine \\ e-mail: 803555474021@gmail.com,orcid.org/0000-0002-5753-0382 \\ Valerii Levchenko \\ Professor, Head of the Department, Ivano-Frankivsk National Medical University, Ukraine \\ e-mail: awgust52@gmail.com,orcid.org/0000-0002-6896-9710 \\ Antoni Stadnicki \\ Professor, Ph.D., Polonia University in Czestochowa, Interdisciplinary Faculty, Poland \\ e-mail: astadnic@wp.pl, orcid.org/0000-0003-2675-3732
}

\section{Summary}

In recent years, the study of the structural and functional state of the retina in patients with the hypertension stage of the I-IInd type with the usage of optical coherence tomography with angiography, is the subject of particular interest.

It was examined 54 patients with the I- II stage of hypertension, aged 35 to 62 years, who did not receive antihypertensive therapy. Visualization of retinal structures was performed using an optical coherence tomograph (RTVue XR Avanti OCTA (Optovue, Inc, with AngioVue Software 2.0) with angiography function.

A decrease in visual acuity was found in $56.67 \%$ of patients with hypertension of the I stage, and - in $79.17 \%$ of patients with the II stage.

From the retinal arterioles it was detected an increase in their tone, especially among patients with hypertension of the II stage. On the part of capillaries, among patients of the main group, their tortuosity was noted - in $62.5 \%$ of patients with the II stage of $\mathrm{AH}$, also in $54.17 \%$ of cases it was revealed a granular blood flow. Also among this group of patients, microaneurysms were revealed in a third of patients, areas of depletion were revealed in $41.67 \%$ of patients.

Among extravascular disorders, in patients with I-II degree AH, were revealed hemorrhages, retinal edema, thickening of the neuroepithelium and pleximorphic layer, smoothing of the foveolar fossa, edema of the macular area, also it was detected accumulation of fluid between the layers.

The study of the peripapillary zone of the retina revealed a significant thickening of the layer of nerve fibers in patients with the I stage of $\mathrm{AH}$ up to $(176.4 \pm 9,75) \mu \mathrm{m}$ in $33.33 \%$ of people, under the II stage - to $(190,24 \pm 12,53) \mu \mathrm{m}$, in $54.17 \%$ of cases, against the index rules $-(102.5 \pm 6,47) \mu \mathrm{m}$. In $12.5 \%$ of cases, the RNFL index was significantly lower than the obtained norm $-(93.78 \pm 6.19) \mu \mathrm{m}$.

Currently, it is necessary to continue the study of the retina in patients with hypertension to determine the risks of damage caused to target organs and evaluate the effectiveness of prescribed antihypertensive therapy.

Keywords: target organs, retina, fundus, visometry, vascular changes, non-contact angiography.

DOI: https://doi.org/10.23856/4533 


\section{Introduction}

Currently, arterial hypertention is one of the leading problems of modern medicine, not only due to the wide spread of the disease among the population, but also the place that it occupies in the structure of mortality and growth of disability.

The nature of the vascular bed changes - from the main blood vessels to the capillaries at the arterial hypertension ( $\mathrm{AH}$ ) shows the clinical course of the disease, the effectiveness of antihypertensive therapy designed, and the risks of possible complications.

Stress integral formation of hypertension accompanied by mental disintegration, and neurohormonal somatovegetativnyh processes, with the entire range of stress-realizing and stress-limiting effects occur at the level of microcirculatory (ICR), cellular metabolism (Park, 2016:36; Forouzanfar, 2017:2). This disturbance in microcirculatory line subtly reflects changes not only in hemodynamics, but the system homeostasis in general, the development of compensatory or pathological reactions (Khaisheva, 2013:49; Hoppe, 2007: 25).

In recent years, of particular interest are studies of the retina as part of the "exposed" brain in patients with hypertension. From this perspective it is assumed that the processes that occur in the blood vessels and nerve ganglia retina is the reflection process along certain areas of the brain. Therefore explore spare condition in the retina - changes of its structures and functions at the background of hypertension, a condition of its blood supply, will indirectly give the understanding of the features of intracranial blood flow in the basin a. ophthalmica, branches of the anterior and middle cerebral arteries, and it is also possible to detect certain functional changes in these parts of the brain at the background of a permanent increase of blood pressure.

The microcirculatory tract, is the place where the transport function of the cardiovascular system, is ultimately realized and transcapillary exchange takes place. The bulk of intravascular continuum, in the formation of high blood pressure, is formed in the MC system (Hussain, 2017:27). Therefore, the study of characteristics of microvascular hemodynamics and structure of the retina let us understand the early mechanisms of formation, features of the course and the risks of hypertension complications, as well as the effectiveness of prescribed therapy.

In this time ophtalmoscopic research is a mandatory element of the examination of patients with hypertension. At the same time we know that routine at ophtalmoscopic diagnostic has some limitations and sometimes low diagnostic value, especially in the early stages of hypertension, under the study of ultra- structural characteristics of the retina. Early objectification of the condition of blood vessels and nerve cells of the retina in arterial hypertension using a valid diagnostic equipment makes it possible to take a step forward and identify in a timely maner the risks and possible degree of early damage to target organs (Khaisheva, 2013:49; Jumar, 2018:11). Now there is a close connection between retinal and cerebral vascular bed and the identity of the ultrastructure of the walls retinal capillaries and capillary ultrastructure CNS. In $82 \%$ of cases, changes in the vessels of the retina and brain in patients with $\mathrm{AH}$ are similar (Chobanian, 2003:289). At the same time it is found that the nature of changes in retinal blood flow can act as a predictor of stroke, CHD (Schneider, 1993:24).

Therefore, in clinical practice study of the structural and functional condition of the retina, features its blood supply through the use of modern non-invasive methods, including optical coherence tomography is relevant, as it allows to detect early changes in the retina of the eye, which is especially important in the treatment of primary and asymptomatic manifestations of $\mathrm{AH}$ and to predict the risks of possible complications and the effectiveness of prescribed treatment. 
Objective: To investigate the structural and functional and condition of the retina hypertension I-II stage using optical coherence tomography with angiographic function.

\section{Materials and methods:}

The study was based on data from 54 patients with hypertension I-II stage, aged 35 to 62 years, who formed the main group.

The criterion for including the patients to the patient population was them being diagnosed with hypertension in accordance to MOH Ukraine № 384, 2012, amendments Ukrainian Heart Association for the prevention and treatment of hypertension (2014), guidelines for the conduct of hypertension European Society of Cardiology and the European Society for arterial hypertension (Triantafill, 2014:8; Jumar, 2018:11; Khaisheva, 2013:3). The severity of hypertension was determined in I - II stage of the disease.

The study did not include patients with hypertension of III stage, with signs of chronic coronary heart disease, heart failure, cerebral circulatory disorders, chronic bronchopulmonary pathology, diabetes, kidney and peripheral artery disease, hypertensive neuropathy.

To the control group with practically healthy people were included 14 persons of the same age (44-56 years) who do not show any ophtalmopatological diseases.

Patients in both groups were examined in an public polyclinic number 3 Ministry of Ukraine, and ophthalmologic center "Optics of your City", Ivano-Frankivsk.

During the research, except for routine diagnostic methods - measurement of blood pressure, ECG, visometry and blood pressure monitor it was used special ophthalmic techniques visualization of the structures of the retina with optical coherent tomography and (RTVue XR Avanti OCTA (Optovue, Inc, with AngioVue Software 2.0) with real-time angiography function.

Use of small size OCT-angiograms $(2 \times 2 \mathrm{~mm}, 3 \times 3 \mathrm{~mm})$ allowed to get better visualisaton of small vasculature, retinal capillaries and choroidocapillaris, while images were more larger caliber and will Roux $(6 \times 6 \mathrm{~mm}, 8 \times 8 \mathrm{~mm})$ showing the condition of large vessels.

In addition, for the evaluation of images of macular and optic nerve fibers mode $\mathrm{ONH}$ was used. In order to determine the thickness of the layer of ganglion cell and the inner plexiform layer it was used complex mode angiography (Kotlyar, 2007:64; Lee, 2018:9; Jia, 2012:20).

Thus OCT-A was used for evaluating the condition of the superficial not only vessels and networks, but also the layer of nerve fibers, the layer of ganglion cells, the deepest vascular plexuses (vascular mesh inner nuclear layer of ) ofthe retina, each of which has an independent pathophysiological and practical significance (Park, 2016:11).

Moreover, the state of FAZ (foveal avascular zone), the densit of the macula and fovealar zone were also evalueted (Hussain, 2016:27; Yu, 2015:5).

Patients, who met the criteria in 10-14 days before the research, stopped taking hypertensive therapy, which was prescribed before. If case of increasing of the blood pressure during this period, short-acting antihypertensive agents were precribed. Also, patients were not receiving assigned before antihypertensive agents, disaggregants, hipolipidemic and vasoactive drugs.

The research was performed in accordance to the requirements of the Helsinki Declaration, all patients signed a voluntary information agreement in order to participate in.

For statistical processing of the data obtained during the study it was used a package of computer programs Microsoft Excel Started 2016, Statistica 10.0 (StatSoft Inc.). The criteria of Kolmogorov-Smirnova was used to check the hypothesis of adequet distribution. The significance of quantitative difference was evaluated using Student's t-test for an independent sample. The difference was considered significant at $\mathrm{p}<0,05$. 


\section{Results and their discussion}

During the research it was found that the I st. AH was revealed in 30 patients, men and women - 12 and 18, respectively; 24 people were diagnosed with II st. AH, 9 men and 15 women, respectively. In patients with I st. AH systolic blood pressure (SBP) was $148,4 \pm 3,06 \mathrm{~mm} \mathrm{Hg}$, (DBP) $-74,4 \pm 1,18 \mathrm{~mm} \mathrm{Hg}$. ; in patients with II st. hypertension SBP was $152,67 \pm 2,16 \mathrm{~mm} \mathrm{Hg}$, DBP $-84,63 \pm 1,78 \mathrm{~mm} \mathrm{Hg}$. Blood pressure among the control group was: $\mathrm{CBP}-128.2 \pm 1.86 \mathrm{~mm} \mathrm{Hg}, \mathrm{DBP}-76.54 \pm 0.69 \mathrm{~mm} \mathrm{Hg}$.

According to the performed visometry, visual acuity was significantly reduced among $56.67 \%$ of patients with hypertension of the I degree and was up to $0.46 \pm 0.04$, among patients with II stage of arterial hypertension visual impairment was found in $79.17 \%$ of people in this group $-0.35 \pm 0.06$. In the control group, the index and visual acuity were $-0.86 \pm 0.04$.

Ophthalmoscopic picture, according to OCT among patients of I-II stage of AH, was presented by the results of these vascular and perivascular research.

The detected vascular changes were common for patients with I-II stage of AH.

They included arterial and venous caliber irregularities, microaneurysms, vascular tortuosity, spasm and pulsation of arterioles, intermittent blood flow, areas of stasis, the presence of redness areas and depletion, the presence of collaterals.

Among extravascular disorders, that were found in patients with I-II stage of AH, single or multiple hemorrhage was noted, swelling of retinal thickening, neuroepithelium and plexymorhpic layer, so called the type of "cotton wool spot", which could even lead to irreversible loss of nerve fibers of retina, smoothed on art and foveolar pits, swelling of the macular area, accumulation of fluid between the layers cystic formations.

The condition of retinal arterioles in patients with hypertension I-II. (\%) according to OCT-A

\section{*PULSATION DURING THE EXAMINATION *SEGMENTAL SPASM OF ARTERIOLES *TORTUOSITY OF ARTERIOLES *MICROANEURYSMS}

*UNEVEN CALIBER

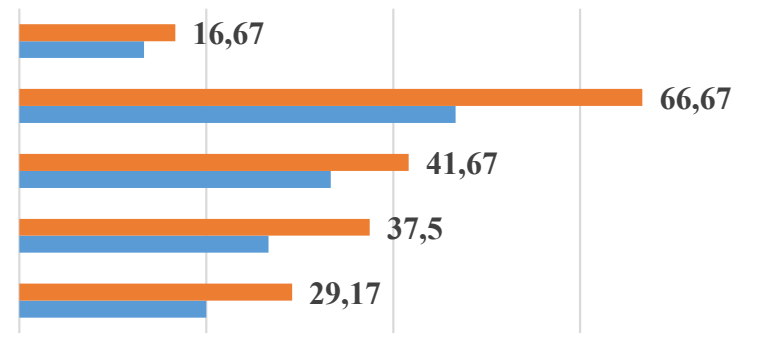

0

$$
\square \text { II CT } \square \text { I CT }
$$

\section{Figure 1. presents the changes found in the retinal arterioles in patients with I-II stage hypertension}

Thus, it was found that most often the retinal arterioles show an increase in their tone, especially among patients with hypertension of the II stage $(66,67) \%$, against $(46,67) \%$ of the indicator obtained at East AH. Their tortuosity and the presence of microaneurysms were also often detected, uneven caliber of arterioles. In a small number of patients, vascular pulsation 
was noted during the study, which is not observed in healthy people. The above changes were mostly found among patients with II stage of $\mathrm{AH}$.

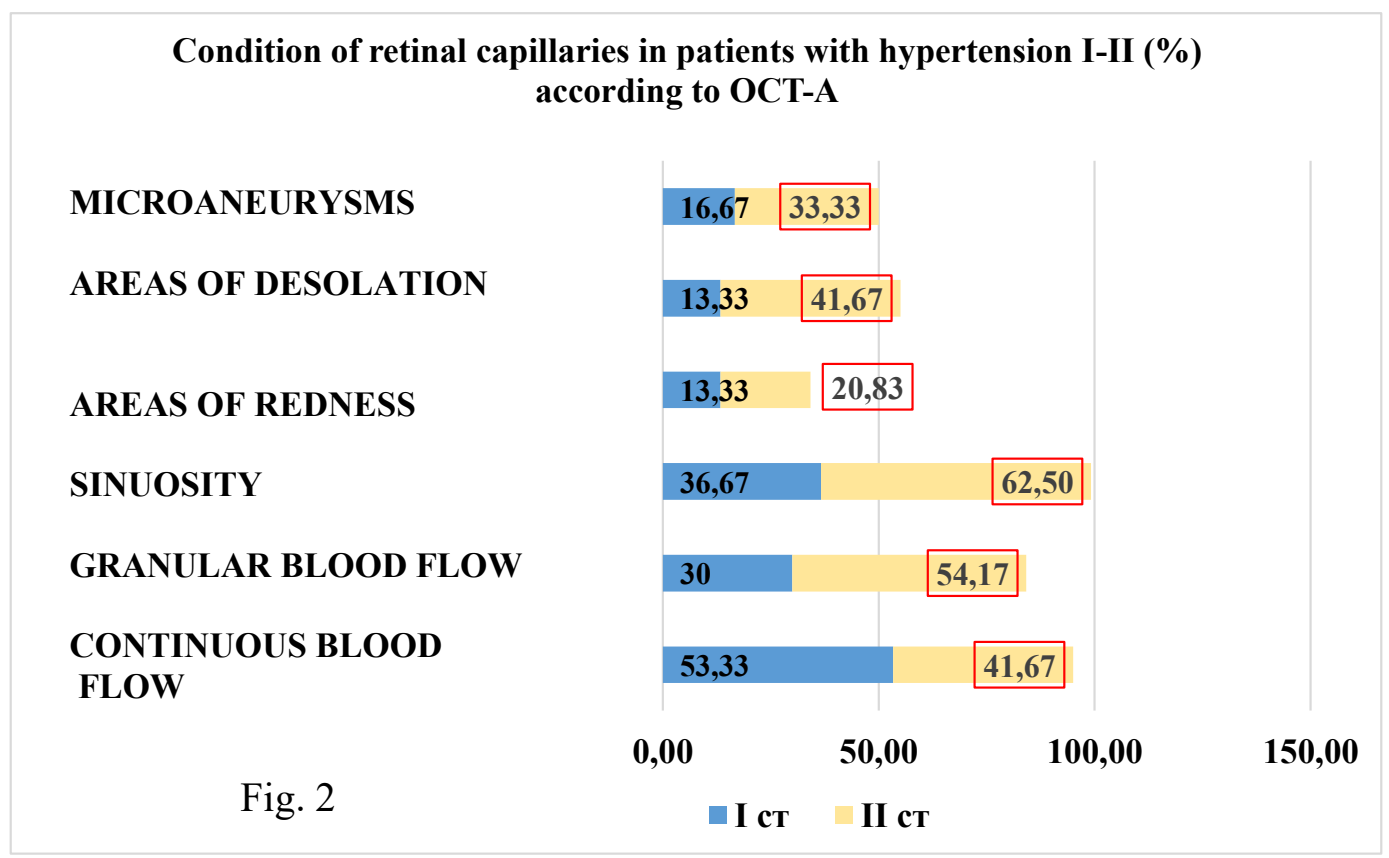

Figure 2. The results of the study of the condition of the retinal capillaries in patients with I-II stage of AH

It was found that most changes in the capillaries of patients from the main group were recorded as they wriggle - in $62.5 \%$ in patients with the II stage of $\mathrm{AH}$, also in $54.17 \%$ of cases there was a granular, intermittent blood flow. Also among this group of patients, a third of patients had microaneurysms, $41.67 \%$ of patients had areas of depletion (not reperfusion), which indicates ischemia. Moreover, among patients, the decrease in total MC was mostly observed in the paramacular area. In patients with I stage of $\mathrm{AH}$, changes on the part of the retinal capillaries also took place, but were found much less frequently than in the group of patients with II stage of $\mathrm{AH}$, except for the rate of continuous blood flow, which was higher and was observed in $53.33 \%$ of cases.

It should also be noted, that in some patients $(n=9)$ with the II stage of AH, it was detected isolated signs of stasis, which was not observed in the patients with the It stage of AH.

Regarding retinal veins, they also underwent significant changes, which are often combined with each other and confirm the systemic and failures in hypertension (Table 1).

During ophthalmoscopy, half of the examined patients showed a dark shade of veins, their dilatation - from moderate to significant, often with tortuosity of the veins. The venous plethora, that was revealed at the same time, indicates that part of patients with the I-II stage of $\mathrm{AH}$, face problems with blood flow, which leads to varicose veins, venules and the risk of stagnation with its subsequent consequences. In addition, in some patients with moderate dilatation and venous plethora, the collateral network was significantly manifested. 
In general, this indicates the progression of changes in the fundos, especially in paatients with the II stage of AH. In the control group of patients, against the background of normotension, there were only isolated cases of uneven venous caliber and moderate dilation. In the fundos, except for modified forms of vessels, in patients from the main group, were also found bleeding and white lesions, confirming the mechanisms of retinal involvement in the process of alteration and degenerative changes.

Table 1

Characteristics of the retinal veins among patients with hypertension I-II st.

\begin{tabular}{|l|c|c|c|}
\hline \multirow{2}{*}{$\begin{array}{c}\text { Types of retinal } \\
\text { vein disorders }\end{array}$} & \multicolumn{2}{|c|}{ Arterial hypertension (\%) } & \multirow{2}{*}{$\begin{array}{c}\text { Control group } \\
\text { (n= 1 4) }\end{array}$} \\
\cline { 2 - 3 } & Stage I (n=30) & Stage II (n= 24) & 14.29 \\
\hline Caliber unevenness & 33.33 & 45.83 & \\
\hline Wreegle & 40,0 & 66.67 & 14.29 \\
\hline Moderate expansion & 33.33 & 33.33 & \\
\hline Saccular extension & 10 & 29.17 & \\
\hline Sharp dilatation & & 25 & \\
\hline Pendulous blood flow & 13.33 & 20.83 & \\
\hline Venous plethora & 36.67 & 58.33 & \\
\hline
\end{tabular}

During the study of the retina on the periphery were found retinal hemorrhages in the form of stripes, in the patients with I stage of $\mathrm{AH}-23.33 \%$, and in $41.67 \%$ of patients with the II stage of hypertension. Hemorrhages along the vessels of nerve fibers, around the OD. were also detected in $6.67 \%$ and $20.83 \%$ of cases, respectively, in the patients with I and II stage of AH. Their formation is often associated with the loss of compactness nerve cells, hidden microaneurysms, diapedesis of erythrocytes microtrombosis against the background of increased blood pressure (Aznabayev, 2015:248; Chalam, 2016:11).

Also in some patients, there were revealed single hemorrhages in the outer plexiform layer on the background of relevant clinical symptoms.

Detected disorders of microcirculation, stagnation, tissue hypoxia, impaired permeability of cell membranes may be the trigger for the development of edema of the layers in the macular area in hypertensive patients (Lavia, 2019:39; Schneider, 1993:24). During the study it would be established that such pathological changes were observed not only among patients with II st. of AH, but also among patients with I st. arterial hypertension (Table 2).

Table 2

Characteristics of retinal structural changes among patients with hypertension I-II

\begin{tabular}{|l|c|c|}
\hline \multirow{2}{*}{\multicolumn{1}{c|}{ Types of structural retinal changes }} & \multicolumn{2}{c|}{ Arterial hypertension (\%) } \\
\cline { 2 - 3 } & I st. (n= 30) & II st. (n = 24) \\
\hline Retinal edema( peripapillary and macular areas) & 30 & 54.17 \\
\hline Deformation of the foveolar contour (profile) & 13.33 & 29.17 \\
\hline Smoothing of the foveolar fossa & 20 & 58.33 \\
\hline Thickening of the layer of nerve fibers & 10 & 54.17 \\
\hline Accumulation of fluid between the layers of the retina & 13.33 & 41.67 \\
\hline Cystic formations (inner nuclear layer) & 16.67 & 37.5 \\
\hline Cotton-shaped formations(plexiglass layer) & 23.33 & 37.5 \\
\hline
\end{tabular}


Thus, according to OCT-A in $30 \%$ of patients with I st. of AH it was observed retinal edema, in patients with II st. of AH - it occurred in $54.17 \%$ of cases (Table 2).

In the peripapillary and paramacular zones, retinal cotton-like "exudates" of gray color of various sizes, without clear boundaries, were also observed. The appearance of cotton-shaped foci is associated with the occlusion of the microcirculatory tract in this area.

In addition, 3 patients with II AH marked swelling of the OD in the form of light smearing, blurred edges.

The accumulation of fluid in the interlayer space in some patients with hypertension I-II can pose a threat to compression of blood vessels, ganglion cells.

Study of the condition of the peripapillary zone of the retina in patients with hypertension I-II found at on the fat spare nerve fiber layer (SNF - RNFL), during the first degree AH to $(176.4 \pm 9,75) \mu \mathrm{m}$ in $33.33 \%$ of persons, against the norm - $(102.5 \pm 6,47) \mu \mathrm{m}$ obtained in the control group $(\mathrm{p}<0.05)$. In patients with II hypertension in $54.17 \%$ of the thickness and SNF Estates la $(190,24 \pm 12,53) \mu \mathrm{m}$, significantly dominating the norm among the remaining patients of this group in $12.5 \%$ of cases, the thickness SNF was significantly lower than the resulting rules $-(93,78 \pm 6,19) \mu \mathrm{m}$.

Hemorrhages detected during examination in some patients with hyper tension may obscure the macroaneurysm.

When examining patients with hypertension I-II. the decrease in the density of the macula at the level of the superficial and deep venous plexuses, as well as the deepening of the foveolar avascular zone was revealed in some of them.

Quantitative assessment of the macular and peripapillary vascular network using OCT angiography revealed a decrease in vascular density in some patients with hypertension. Reduction of peripapillary and macular microcirculation in the retina in patients with hypertension, perfusion defects may precede structural changes in OD and visual field defects. In such a situation, the rate of loss of vascular density in the macular area may exceed the rate of loss of ganglion cells of the macular area (Aznabayev, 2015:248; Lumbroso, 2014:208).

Table 3. according to OCT-A presents the thickness of the individual layers of the retina. Thus, it was found that most often changes in the thickness of the retinal layers in the form of their significant thinning were found among patients with II st. AH in the upper and lower quadrants in the macular layers of nerve fibers, layers of ganglion cells, pleximorphic layer.

At the same time, patients with I st., significant thinning of hypertension was observed only on the part of the ganglion cell layer. It was found that in some patients with II the disease, it was marked the thickening of the inner nuclear layer. Thus, studies of the characteristics of the retinal layers with the help of OCT-A indicate a certain relationship between the stages of hypertension and changes in visual function and the development of retinopathy.

Also attention was given to correlation links between the level spasm of arteriolar tortuosity and reduction of their visual acuity $(r=-0,478 ; \mathrm{p}<0.01)$, between wriggle with dough capillaries, blood flow and granular layer, the thickening of macular nerve retinal fibers $(\mathrm{r}=0,416 ; \mathrm{p}<0,05)$. 
Table 3

The state of retinal layer thickness in patients with hypertension and in the control group $(\mu \mathrm{m})$

\begin{tabular}{|c|c|c|c|}
\hline \multirow{3}{*}{$\begin{array}{l}\text { Indicatorsof retinal } \\
\text { layer thickness }\end{array}$} & \multicolumn{2}{|c|}{ Hypertension } & \multirow{2}{*}{ Control on thegroup } \\
\hline & I st. & II st. & \\
\hline & 1 & 2 & 3 \\
\hline $\begin{array}{l}\text { macular layer of nerve fibers:- } \\
\text { upper quadrant- lower quadrant }\end{array}$ & $\begin{array}{l}119.4 \pm \\
12,6692,51 \pm \\
8,86\end{array}$ & $\begin{array}{l}102,11 \pm 7,16 \\
\text { p } 1-2>0,5 \\
86,51 \pm 6,86 \\
\text { p } 1-2>0,5\end{array}$ & $\begin{array}{l}123,74 \pm 10,36 \mathrm{p} 1,2- \\
3<0,05 \\
112,61 \pm 7,14 \\
\text { p1,2-3<0,05 }\end{array}$ \\
\hline $\begin{array}{l}\text { layer of ganglion cells:- upper } \\
\text { quadrant- lower quadrant }\end{array}$ & $\begin{array}{l}96,17 \pm 5.0690 \\
26 \pm 4.78\end{array}$ & $\begin{array}{l}81,45 \pm 5.74 \mathrm{p} 1- \\
2<0.0577 .22 \pm \\
6.11 \mathrm{p} 1-2<0.05\end{array}$ & $\begin{array}{l}96.57 \pm 6.73 \mathrm{p} 2- \\
3<0.0594 .85 \pm 6.12 \mathrm{p} 2- \\
3<0.05\end{array}$ \\
\hline $\begin{array}{l}\text { inner plexiglass layer :- upper } \\
\text { quadrant- lower quadrant }\end{array}$ & $\begin{array}{l}68,36 \pm \\
3.9262 .68 \pm 4.16\end{array}$ & $\begin{array}{l}66.42 \pm 3.81 \mathrm{p} 1- \\
2>0.560 .73 \pm \\
4.07 \mathrm{p} 1-2>0.5 \\
\end{array}$ & $\begin{array}{l}77.38 \pm 4.28 \mathrm{p} 1,2- \\
3<0,0573,22 \pm \\
5,12 \mathrm{p} 1,2-3<0,05 \\
\end{array}$ \\
\hline $\begin{array}{l}\text { inner nuclear layer- nasal } \\
\text { quadrants }\end{array}$ & $31.15 \pm 1.67$ & $\begin{array}{l}35.69 \pm 3.10 \mathrm{p} 1- \\
2>0.5\end{array}$ & $\begin{array}{l}26.35 \pm 2.78 \mathrm{p} 1.2- \\
3<0.05\end{array}$ \\
\hline $\begin{array}{l}\text { Outer plexiglass layer- nasal } \\
\text { quadrants }\end{array}$ & $23.6 \pm 2.43$ & $\begin{array}{l}27.12 \pm 3.16 \mathrm{p} 1- \\
2>0.5\end{array}$ & $\begin{array}{l}18.51 \pm 1.84 \mathrm{p} 1.2- \\
3<0.05\end{array}$ \\
\hline
\end{tabular}

\section{Discussion}

Despite the recommendations of the European Society of Cardiology and the European Society of Arterial Hypertension of 2003 (ESH / ESC, 2003) to the exclusion of the eye from the list of target organs, a report of the National Committee on prevention, diagnosis and treatment of high blood pressure USA (JNC7) retinopathy is recognized as one of the significant markers of target organ damage in hypertension. Based on the recommendations of JNC7, the presence of retinopathy may be the basis for initiating antihypertensive drug treatment, even in patients with first-degree hypertension who have no other target organ lesions (Chobanian, 2003:289; Plante, 2002:51; Schneider, 1993:24).

Currently, there is no consensus on the need for retinal examination in patients with hypertension to determine the degree of cardiovascular risk and assess the effectiveness of prescribed antihypertensive therapy. Although previous discussion cases took place before the advent of valid digital diagnostic technologies.

The existing temporary inconsistency in the definition of the eyes as the target organs, the need to study the state of the retina with hypertension, dictates the need for continued scientific research in this direction.

We found that hypertensive retinopathy does not always correspond to the duration and severity of hypertension: so against the background of the first degree hypertension next to the picture of the normal fundus, in the rest of the patients there are lesions of the retinal structures, which do not exclude asymptomatic cerebral lesions.

The degree of microcirculation disorders in hypertension is one of the key markers that may indicate damage to target organs. It is a violation of the microcirculatory tract subtly reflect the early changes in the central hemodynamics, homeostasis, the development of compensatory or pathological reactions in the fluctuations of blood pressure (Hoppe, 2007:10). 
The method of OCT-A for diagnostic informativeness outweighs the results of other methods of capillaroscopy, including using injectable angiography. OCT-A allows to detect morphological and functional changes of the retina in the early stages of hypertension, to monitor them, to monitor the course of the disease and the effectiveness of prescribed treatment. And also timely diagnose the risks of possible acute and chronic complications.

The study confirmed the relationship between systemic hypertension, deterioration of the microcirculatory tract and the structural picture of the retinal layers on the background of decreased visual acuity. The most important issue is to assess the impact of prescribed antihypertensive therapy on the microcirculatory tract, as a trigger link that provides the interaction of metabolic, neurohumoral, structural, endothelium-dependent and other factors affecting the reactivity of the vascular wall.

\section{Conclusion}

In the light of the achievements of modern technologies of eye examination in the treatment of hypertension, the method of optical coherence tomography should be included in the mandatory screening diagnostic tests at the level of primary health care.

Simultaneous assessment of the structural and functional state of the retina using OCT-A allows you to get a better idea of the degree and risks of target organs in hypertension, the risks of possible acute complications that occur in hypertension in a particular patient. Which contributes to a more accurate definition of the target blood pressure and improvement of therapeutic tactics.

An important stage of the study is to study the effect of prescribed antihypertensive therapy on the morphofunctional state of the retina in patients with hypertension. The resulting positive dynamics of the detected retinal changes in hypertension - improvement of retinal microcirculation, neuroepithelium under the influence of prescribed antihypertensive treatment, may indirectly reflect the improvement of cerebral circulation, metabolic support of cerebral structures and generally confirms the correctness or incorrectness of choice.

\section{References}

Aznabaev B.M., Mukhamadeev T.R., Dibaev T.I. (2015). Opticheskaya kogerentnaya tomografiya + angiografiya glaza [Optical coherence tomography + angiography of the eye]. Moskow: August Borg. (in Russian)

Chalam, K. \& Sambhav, K. (2016). Optical coherence tomography Angiography in retinal diseases. Journal of Ophthalmic Vision and Research. 11 (1), 84 - 92. Retrieved from: https:// pubmed.ncbi.nlm.nih.gov/27195091/(accessed 15 January 2021).

Chobanian, A.V., Bakris, G.L., Black, H.R. et al. (2003). For the National Heart, Lung, and Blood Institute Joint National Committee on Prevention, Detection, Evaluation, and Treatment of High Blood Pressure; National High Blood Pressure Education Program Coordinating Committee. The Seventh Report of the Joint National Committee on Prevention, Detection, Evaluation, and Treatment of High Blood Pressure. JAMA. 289 (7), 2560 - 71.

Forouzanfar, M.H., Liu, P., Roth, G.A. et al. (2017). Global burden of hypertension and systolic blood pressure of at least 110-115 mm Hg. JAMA. 317 (2), 165 - 82.

Hagag, A.M., Gao, S.S. \& Huang, D. (2017). Optical coherence tomographic angiography: Technical principles and clinical application in ophthalmology. Taiwan J. Ophthalmol. 7 (3), 115-29. 
Hoppe, S.A., Antonis, P., Adam, D., et al. (2007). Arterial pulsewave velocity but not augmentation index is associated with coronary artery disease extent and severity: implications for arterial transfer function applicability. J. Hypertens. 25(10), $2105-09$.

Hussain, N., Hussain, A. (2016). Diametric measurement of foveal avascular zone in healthy young adults using optical coherence tomography angiography. Int. J. Retin. Vitr. 2 (1), 27.

Jia, Y., Tan, O., Tokayer, J., Potsaid, et al. (2012). Amplitude-decorrelation angiography with split spectrum with optical coherence tomography. Optics express. 20 (4), $4710-25$.

Jumar, A. at al., (2018). Improving retinal capillary thinning after valsartan treatment in patients with hypertension. J. Wedge. Hypertension (Greenwich). 18 (11), $1112-8$.

Kanski, D. (2009). Clinical ophthalmology: a systematic approach / 2nd ed.; - Wroclaw: Elsevier Urban \& Partner. -944 p.

Khaisheva L.A., Shlyk S.V., Glova S.E., Bykovskaya T.Yu. (2010). Farmatsevticheskoya korektsiya sosudestikh narusheniy v bol'nikh na arterial'noyu gipertenziyu [Pharmaceutical correction of vascular disturbances in patients with arterial hypertension]. Russian Journal of Cardiology. Vol.10. No.5. pp.35-40. Retrieved from: https://russjcardiol.elpub.ru/jour/article/ view/1492?locale $=$ en (accessed 10 January 2021).

Kotlyar K.E., Drozdova G.A., Shamshinova A.M. (2007). Gemodinamika oka ta suchasni metodi yogo doslidzhennya. Chastina III: Neinvazivni metodi krovopostachannya ochey [Hemodynamics of the eye and modern methods of its research. Part III: Non-invasive methods of eye blood supply] 2. pp. 64-71. Retrieved from: https://cyberleninka.ru/search?q=Kotlyar\%20K.E.\%2C\%20 Drozdova\%20G.A.\%2C\%20Shamshinova\%20A.M.\&page=1 (accessed 17 January 2021).

Lavia, C., Bonnin, S. and others. (2019). Vessel density of superficial, intermediate and deep capillary plexuses using optical coherence tomography Angiography. Retina. 39(2), 247 - 258. Lee, W.H. et al. (2018). Microvascular changes of the retina in hypertension, measured by optical coherence tomography Angiography. Scientific reports. 9(156), 1 - 7.

Lumbroso, B., Ristoli, M. (2014). Optical coherence tomography. A practical guide. / Per. with English M.: Panfilov Publishing House; BINOM. Laboratory of Knowledge. - 208 p.

Park J.J., Soetikno B.T., Fawzi A.A. (2016). Characterization of the Middle Capillary Plexus Using Optical Coherence Tomography Angiography in Healthy and Diabetic Eye. Retina. 36 (11), $2039-50$.

Plante, G.E. (2002). Vascular response to stress in health and disease. Metabolism. 51 (6), $25-30$.

Sampson, D.M. et al. (2017). Influence of axial length variation on retinal vascular surface density and measurement of avascular zone area of foveal zone by means of optical coherence tomography Angiography. Retina. 58 (7), 3065 - 72.

Schneider, R., Rademacher, M., Wolf, S. (1993). Lacunar infarcts and white matter attenuation: ophthalmologic and microcirculatory aspects of the pathophysiology. Stroke. 24, 1874-1879. Triantafill, A. and others. (2014). Accumulation of microvascular lesions of target organs in newly diagnosed patients with hypertension. J Am Soc Hypertens. 8, 542.

Tultseva S.N., Astakhov Y.S., Rukhovets A.G., Titarenko A.I. (2017). Informativnost' OST-angiografy" $v$ sochetanii s isledovaniyami regional'noy gemodinamiki pri oklyuzii ven setchatki [Informativeness of OCT-angiography in combination with researches of regional hemodynamics at an occlusion of retinal veins]. Ophthalmol. statements. vol. 10. no. 2. pp. 40. Retrieved from: https://www.researchgate.net/scientific-contributions/A-G-Rukhovets-2129752686 (accessed 20 February 2021).

Yu, J., Jiang, C., Wang, X. et al. (2015). Macular perfusion in healthy chinese: An optical coherence tomography angiogram study. Investig Ophthalmol. Vis. Sci. 561(5), 3212 - 17. 